\title{
Lipodystrophy defined by Fat Mass Ratio in HIV-infected patients is associated with a high prevalence of glucose disturbances and insulin resistance
}

Paula Freitas ${ }^{*}$, Davide Carvalho², Ana Cristina Santos ${ }^{3}$, Joana Mesquita ${ }^{4}$, Maria João Matos ${ }^{5}$, Antonio Jose Madureira ${ }^{6}$, Esteban Martinez ${ }^{7}$, António Sarmento ${ }^{8}$ and José Luís Medina ${ }^{9}$

\begin{abstract}
Introduction: Combined antiretroviral therapy (CART) in the treatment of HIV-1 infection has been associated with complications, including lipodystrophy, hyperlipidaemia, insulin resistance (IR) and diabetes.

Aims: To compare the prevalence of glucose homeostasis disturbances and IR in HIV patients on CART according to the presence of lipodystrophy (defined clinically and by Fat Mass Ratio) and different patterns of fat distribution and to establish their associations.

Design: Cross-sectional cohort study.

Methods: We evaluated body composition and IR and insulin sensitivity indexes in $345 \mathrm{HIV}$-infected adults.

Results: Patients with clinical lipodystrophy $(\mathrm{CL})$ had higher plasma glucose levels than patients without $\mathrm{CL}$, without significant differences in plasma insulin levels, A1c, HOMA-IR, HOMA-B, QUICKI, or MATSUDA index. Patients with lipodystrophy defined by FMR had higher plasma glucose and insulin levels, A1C, HOMA-IR, QUICKI and MATSUDA than patients without lipodystrophy, without differences in HOMA-B. Higher insulin resistance (HOMA-IR $\geq 4$ ) was present in patients with FMR-defined lipodystrophy. Patients with FMR-defined lipodystrophy had a higher prevalence of IFG, IGT and DM than patients without lipodystrophy. Significant associations between HOMA-IR and total, central and central/peripheral fat evaluated by $C T$ at abdominal level were found and no association between HOMA-IR and peripheral fat. Association between HOMA-IR and total and trunk fat but no association with leg and arm fat (evaluated by DXA) was found.
\end{abstract}

Conclusions: IR and glucose disturbances were significantly increased in patients with FMR-defined lipodystrophy. FMR lipodystrophy definition seems to be a more sensitive determinant of insulin resistance and glucose disturbances than clinical definition.

Keywords: Lipodystrophy, Insulin resistance, HIV, Glucose homeostasis disturbances

\footnotetext{
* Correspondence: paula_freitas@sapo.pt

${ }^{1}$ Department of Endocrinology, Hospital de São João, University of Porto Medical School, Alameda Hernâni Monteiro, 4200, Porto Portugal, Portugal Full list of author information is available at the end of the article
} 


\section{Introduction}

Combined antiretroviral therapy (cART) in the treatment of HIV-1 infection confers significant survival benefit and has altered the natural history of this disease [1]. However, cART has been associated with metabolic complications, including hyperlipidemia, insulin resistance (IR), diabetes mellitus (DM) and lipodystrophy, with resultant increased risk of cardiovascular disease [2].

DM is a known complication of several antiretroviral therapies, being associated with both short $[3,4]$ and long-term [5,6] exposure to some of these drugs [7]. The reported prevalence of DM in HIV-infected populations ranges from $2 \%$ to $14 \%$, with differences in prevalence explained by differences in demographic characteristics, lifestyle, and antiretroviral exposure [7-11]. Some studies have suggested an increased risk of premature cardiovascular disease in HIV-infected individuals, and have highlighted the need to understand the relationship of HIV infection and cART with the risk of DM, a primary cardiovascular risk factor [12,13]. Diabetes is associated with IR, and IR among treated HIV-infected patients is multifactorial: in addition to the common contributors to IR (e.g. obesity, physical inactivity and genetic influences), antiretroviral drugs and lipodystrophy or alterations in body fat distribution are also involved [5]. The term "HIV-associated lipodystrophy syndrome" was coined, but it soon became clear that some patients have pure lipoatrophy, while others have central fat accumulation, and a subset of patients have a mixed picture of both morphologic features. As in congenital lipodystrophy, lipodystrophy related to HIV-infected patients is also associated with IR and overt DM $[12,14,15]$.

The aim of this study was to compare the prevalence of glucose homeostasis disturbances and IR in HIVinfected adult patients on cART according the presence of lipodystrophy [clinically defined and FMR-defined determined by whole-body dual-energy X-ray absorptiometry (DXA)] and to different patterns of fat distribution, and to establish the main contributors to these alterations in HIV-infected adults.

\section{Methods}

\section{Subjects}

As part of a cross-sectional cohort study, 345 HIVinfected Caucasian adults, 239 men and 106 women, who were non-institutionalized, were evaluated in the Endocrinology Outpatient Department of São João Hospital, consecutively referred from the Infectious Diseases Clinic. Patients were included on the first visit, and all were on cART. The study protocol was approved by the Hospital Ethics Committee for Health and all patients provided informed consent.

\section{Clinical assessment}

For each patient the following information was collected using a standardized protocol: demographic data (age, gender), duration of HIV infection, HIV infection risk factors, duration of cART and characterization of the infection. We used the "Centers for Disease Control and Prevention" (CDC) criteria for classifying the degree of infection [16]. Clinical history of diabetes, hypertension and use of anti-diabetic, anti-hypertensive and lipidlowering drugs, as well as duration of cART, were also evaluated. Weight, height, circumferences of neck, waist, hip, thigh and arm were measured as previously published [17-20]. Blood pressure (BP) was measured after 5 minutes seated, with the elbow flexed at the heart, using a standard aneroid sphygmomanometer with the cuff on the upper right arm. Two blood pressure readings were taken and the mean of the two readings was calculated. Body mass index (BMI) was calculated as weight divided by height squared $\left(\mathrm{kg} / \mathrm{m}^{2}\right)$. Clinical lipodystrophy was defined as a peripheral lipoatrophy with or without central fat accumulation assessed by both patient and practitioner, as we have previously described [17-20]. Presence of central fat accumulation or abdominal prominence was defined by the measurement of waist circumference using the International Diabetes Federation (IDF) criteria for metabolic syndrome [21].

Patients were classified into 4 different groups according the presence or absence of either clinical lipoatrophy or abdominal prominence: no lipodystrophy - patients without clinical lipoatrophy and without abdominal prominence; isolated central fat accumulation - patients without clinical lipoatrophy and with abdominal prominence; isolated lipoatrophy - patients with clinical lipoatrophy and without abdominal prominence; mixed forms of lipodystrophy - patients with clinical lipoatrophy and with abdominal prominence. The clinical assessment was performed by the same practitioner (PF).

\section{Evaluation of body composition}

Body composition was also assessed with whole-body dual-energy X-ray absorptiometry (DXA - Lunar Expert XL). DXA measurement was performed while the patient was in a supine position, with standard positioning of the arms and feet. Markers used in this study for trunk and lower limbs that defined regions of interest were those indicated by the manufacturer. Regional fat mass values were grouped and analysed for the following anatomical regions: arms, legs, trunk and total body. The fat mass ratio (FMR) is the ratio of the percentage of the trunk fat mass to the percentage of the lower limb fat mass $(F M R=\%$ of the trunk fat mass $/ \%$ of the lower limb fat mass) [22]. We define lipodystrophy by FMR using the cut-off value of 1.961 threshold for men and 1.329 for women [17].The quantification of total, 
visceral, and peripheral fat was performed with a 64slice computed tomography (CT) scanner (Siemens Sensation 64 Cardiac) with the same technique as previously described [23,24]. All values were expressed in $\mathrm{cm}^{2}$ rounded to the nearest centesimal.

\section{Laboratory analysis}

A venous blood sample was drawn after a 12-hour overnight fast. All the samples were analysed at the central laboratory of our hospital. Patients without a previous diagnosis of diabetes were submitted to a glucose tolerance test (OGTT). The test was performed as described by the World Health Organization using a glucose load containing the equivalent of $75 \mathrm{~g}$ anhydrous glucose dissolved in water.

Hepatitis $\mathrm{C}$ was diagnosed by HCV-Ab serostatus. The CD4 cell count was determined by flow cytometry and plasma HIV-1 RNA loads were measured by a quantitative reverse transcriptase polymerase chain reaction (Roche Diagnostic Systems, Inc., Branchburg, NJ, USA), which has a lower limit of detection of 50 copies $/ \mathrm{mL}$.

\section{Definition of the alterations of glucose metabolism}

Diabetes was defined if two consecutive measurements of fasting plasma glucose were $\geq 126 \mathrm{mg} / \mathrm{dL}$ and if $2 \mathrm{~h}$ plasma glucose was $\geq 200 \mathrm{mg} / \mathrm{dL}$ during the oral glucose tolerance test (OGTT).

Alterations of glucose metabolism were defined by American Diabetes Association (ADA) 2009 criteria [25]. We classified patients into 4 different categories of glycaemic profile (normoglycaemia - NG, impaired fasting glucose - IFG, impaired glucose tolerance - IGT and diabetes mellitus type $2-\mathrm{DM}$ ), according to plasma glucose levels at 0' and 120' measured during OGTT.

\section{Measurements of insulin resistance}

IR was defined by the homeostasis model assessment of insulin resistance (HOMA) and insulin sensitivity by the quantitative insulin sensitivity check index (QUICKI) and Matsuda index. These indexes were calculated using the following formulas: HOMA - IR index = (fasting insulin 0x fasting glucose0)/22.5 [26].HOMA B index $=(20 \mathrm{x}$ insulin $0(\mathrm{mU} / \mathrm{mL})) /($ glucose $0(\mathrm{mMol} / \mathrm{L})$ -3.5) [26]. QUICKI $=1 /(\log [$ fasting insulin in $\mathrm{mU} / \mathrm{l}]+$ $\log$ [fasting plasma glucose in $\mathrm{mg} / \mathrm{dL}$ ] [27].Matsuda Index $=10000 /$ sqrt $[$ glyc 0x insulin 0x (glyc mean $\mathrm{x}$ insulin mean $)]$ [28].Glucose expressed in $\mathrm{mmol} / \mathrm{L}$ and insulin inmUI/mL. IR was defined when the value of HOMA > $4[29,30]$.

\section{Statistical analysis}

Statistical analysis was performed using SPSS version 17.0 software (SPSS Inc., Chicago, Illinois, USA). All probabilities were two tailed and $\mathrm{p}$ values $<0.05$ were regarded as significant.
Data were described as mean and standard deviation (SD) for quantitative variables and compared using the Student-t test or the Mann-Whitney test as appropriate. Furthermore, analysis of variance or the Kruskal-Wallis test were used for the comparison between quantitative variables. Categorical variables were described as counts and proportions, and compared using the chi-square or Fisher's exact test.

Spearman correlation coefficients were calculated to estimate the associations between HOMA-IR and body fat mass evaluated either by CT or DXA.

After log transformation, linear regression models were computed for estimating the association between FMR and HOMA score, fasting and 2 hours glucose and A1C levels. Models were adjusted for age, sex, current antiretroviral therapy [protease inhibitor (PI), nucleoside reverse transcriptase inhibitor (NRTI), non-nucleoside reverse transcriptase inhibitor (NNRTI)], CD4 count cells and plasma HIV-1 RNA load.

\section{Results \\ Baseline characteristics}

A total of 345 HIV-infected patients on cART were evaluated with a mean age of $45.0 \pm 11.3$ years. $69.3 \%$ were males. The demographic and clinical characteristics of the patients included in this study, according to the presence of lipodystrophy are shown in Table 1. Patients with clinical lipodystrophy (CL) were older, had higher duration of HIV infection and length of cART. Regarding anthropometric measures, patients with CL had lower BMI, waist, hip, thigh, and arm circumferences. Patients with CL had higher CD4+ cell count and percentage of viral suppression. With regards to the risk of HIV transmission in patients with CL, heterosexuality was responsible for $52.9 \%$, followed by drug addiction in $30.6 \%$, homo-bisexuality in $11.2 \%$. In the remaining cases, haemophilia, transfusions and unknown causes were responsible for $1.2 \%, 1.2 \%$ and $2.9 \%$, respectively. Similarly, in patients without CL, heterosexuality was also the leading cause with $65.8 \%$, followed by drug addiction, homo-bisexuality and unknown causes in $24.6 \%, 8.8 \%$ and $0.9 \%$, respectively. No significant difference was observed in lipodystrophic patients according to HIV risk transmission. The prevalence of co-infection was similar in patients with and without lipodystrophy [clinically- (Table 1) or FMRdefined (data not shown)]. Nevertheless, patients with no lipodystrophy and with isolated peripheral lipoatrophy exhibited a higher proportion of hepatitis $\mathrm{C}$ co-infection when compared to the other two groups (Table 2).

There was a significant difference in the different stages of CDC criteria between patients with or without lipodystrophy, with the majority of patients being in groups $\mathrm{A}$ or $\mathrm{C}$. No differences were observed in the type 
Table 1 Sample characteristics according to the presence of clinical lipodystrophy

\begin{tabular}{|c|c|c|c|}
\hline & Without CL & With CL & $P$ \\
\hline n (\%) & 139 & 206 & \\
\hline \multicolumn{4}{|l|}{ Gender [n (\%)] } \\
\hline Male & $85(61.2)$ & $154(74.8)$ & 0.007 \\
\hline Female & $54(38.8)$ & $52(25.2)$ & \\
\hline Age [years, mean (sd)] & $44.2(12.1)$ & $46.9(10.7)$ & 0.007 \\
\hline $\begin{array}{l}\text { Duration of HIV infection } \\
\text { [years, median (IQR)] }\end{array}$ & $6.0(5.0)$ & $9.0(5.0)$ & $<0.001$ \\
\hline CART [years, median (IQR)] & $4.0(5.0)$ & $8.0(5.0)$ & $<0.001$ \\
\hline Weight $[\mathrm{Kg}$, mean $(\mathrm{sd})]$ & $73.7(14.1)$ & $66.2(12.4)$ & $<0.001$ \\
\hline Height $[\mathrm{m}$, mean $(\mathrm{sd})]$ & $1.65(0.09)$ & $1.66(0.09)$ & 0.368 \\
\hline BMI [(kg/m²), median (IQR)] & $26.3(5.9)$ & $23.8(5.1)$ & $<0.001$ \\
\hline Waist circumference $[\mathrm{cm}$, median (IQR)] & $94.0(17.0)$ & $89.0(14.5)$ & $<0.001$ \\
\hline Hip circumference [cm, median (IQR)] & $99.0(11.0)$ & $91.0(9.0)$ & $<0.001$ \\
\hline Thigh circumference [cm, mean (sd)] & $50.0(5.5)$ & $46.1(6.1)$ & $<0.001$ \\
\hline Arm circumference [cm, mean (sd)] & $28.1(3.1)$ & $26.6(4.1)$ & $<0.001$ \\
\hline Neck circumference [cm, mean (sd)] & $37.2(3.7)$ & $37.1(4.0)$ & 0.940 \\
\hline $\begin{array}{l}\text { CD4 cell count [cells/mm3, } \\
\text { median (IQR)] }\end{array}$ & $446.5(342.2)$ & $544.0(387.0)$ & 0.008 \\
\hline HIV RNA (<50) [n (\%)] & $93(81.6)$ & $163(91.1)$ & 0.017 \\
\hline \multicolumn{4}{|l|}{ Smoking history [n (\%)] } \\
\hline Never & $61(44.2)$ & $70(34.8)$ & 0.219 \\
\hline Current & 55 (39.9) & $93(46.3)$ & \\
\hline Former & $22(15.9)$ & $38(18.9)$ & \\
\hline \multicolumn{4}{|l|}{ HIV risk factor [n (\%)] } \\
\hline Injecting drug user & $28(24.6)$ & $52(30.6)$ & 0.247 \\
\hline Homosexual contact & $10(8.8)$ & $19(11.2)$ & \\
\hline Heterosexual contact & $76(65.8)$ & $90(52.9)$ & \\
\hline Others & $1(0.9)$ & $9(5.3)$ & \\
\hline Hepatitis C co-infection [n (\%)] & $31(25.2)$ & $58(31.4)$ & 0.300 \\
\hline \multicolumn{4}{|l|}{ CDC [n (\%)] } \\
\hline A & $62(54.9)$ & $94(53.4)$ & 0.037 \\
\hline B & $4(3.5)$ & $0(0)$ & \\
\hline C & $47(41.6)$ & $82(46.6)$ & \\
\hline
\end{tabular}

ART [n (\%)]

IP

NNRTI

NRTI

Hypoglycemic therapy [n (\%)]

Oral anti-diabetic drugs

Insulin

Body fat mass by quantitative $\mathrm{CT}$

Total fat $\left[\mathrm{cm}^{2}\right.$, median (IQR)]

Central fat $\left[\mathrm{cm}^{2}\right.$, median $\left.(\mathrm{IQR})\right]$

Peripheral fat $\left[\mathrm{cm}^{2}\right.$, median $\left.(\mathrm{IQR})\right]$

$$
\begin{array}{ccc}
10.1 \%(14) & 14.6 \%(30) & 0.132 \\
4.3 \%(6) & 7.3 \%(15) & 0.261
\end{array}
$$

Table 1 Sample characteristics according to the presence of clinical lipodystrophy (Continued)

\begin{tabular}{lll}
\hline Central/peripheral fat ratio $\left[\mathrm{cm}^{2}\right.$, & $0.51(0.55)$ & $1.34(2.15)<0.001$
\end{tabular}

median (IQR)]

FMR by DXA [median (IQR)]

$1.06(0.57) \quad 1.79(1.37)<0.001$

(CL- clinical lipodystrophy; CDC - Centers for Disease Control and Prevention criteria for staging of HIV infection -; CART- combined antiretroviral therapy; BMI- body mass index; FMR - fat mass ratio; DXA -dual-energy X-ray absorptiometry ; CT - computed tomography; PI - protease inhibitor; NNRTI -non-nucleoside reverse transcriptase inhibitor; NRTI - nucleoside reverse transcriptase inhibitor).

of cART between the two groups of patients, nor in hypoglycaemic therapy (oral anti-diabetic drug and insulin). FMR evaluated by DXA was higher in patients with CL. When body fat mass was evaluated using quantitative CT, patients with CL had lower total and peripheral fat, but higher central/peripheral fat ratio than patients without CL.

No differences in smoking status between patients with or without lipodystrophy [clinically- (Table 1) or FMR-defined (data not shown)] were found. Patients with no lipodystrophy and with isolated peripheral lipoatrophy were more frequently current smokers when compared to the other two groups (Table 2).

\section{Insulin resistance}

No significant differences in the means of HOMA-IR, QUICKI, MATSUDA, insulin and A1c were observed between patients with and without CL. In fact, regarding the alterations of glucose metabolism, only for fasting glucose was there a trend for significantly higher values in CL. On the other hand, when lipodystrophy was defined by FMR, all indicators of insulin resistance and glucose metabolism were significantly associated with lipodystrophy with the obvious exception of QUICKI and MATSUDA indices (Table 3).

Higher prevalence of insulin resistance, defined as HOMA-IR $\geq 4$, was observed in patients with lipodystrophy defined by FMR $(\mathrm{p}=0.019)$ but not when lipodystrophy was clinically defined. Similar results were observed when we compared the prevalence of HOMA score thirds according to the definition of lipodystrophy. Again, only when lipodystrophy was defined by the FMR were the differences between HOMA score thirds statistically significant $(p=0.002)$ (Table 4).

\section{Glucose homeostasis abnormalities}

When we classified patients into the 4 ADA categories of glycaemic profile, no significant differences were found between these categories in patients with or without CL. However, patients with lipodystrophy defined by FMR had a higher prevalence of IFG, IGT and DM when compared to patients without 
Table 2 Smoking history and hepatitis C co-infection according to the four groups of body fat distribution

\begin{tabular}{|c|c|c|c|c|c|}
\hline & $\begin{array}{c}\text { No } \\
\text { lipodystrophy }\end{array}$ & $\begin{array}{c}\text { Isolated central } \\
\text { fat accumulation }\end{array}$ & $\begin{array}{c}\text { Isolated peripheral } \\
\text { lipoatrophy }\end{array}$ & $\begin{array}{l}\text { Mixed forms of } \\
\text { lipodystrophy }\end{array}$ & $\mathbf{P}$ \\
\hline \multicolumn{6}{|l|}{ Smoking history [n (\%)] } \\
\hline Never & $14(28.0)$ & $46(52.9)$ & $24(22.4)$ & $45(48.4)$ & $<0.001$ \\
\hline Current & $30(60.0)$ & $25(28.7)$ & $67(62.6)$ & $26(28.0)$ & \\
\hline Former & $6(12.0)$ & $16(18.4)$ & $16(15.0)$ & $22(23.7)$ & \\
\hline Hepatitis C co-infection [n (\%)] & $19(45.2)$ & $12(14.8)$ & $46(47.9)$ & $11(12.5)$ & $<0.001$ \\
\hline
\end{tabular}

lipodystrophy (Table 5). When patients were stratified into 4 groups of fat distribution (presence or not of clinical lipoatrophy and abdominal prominence), no differences were observed in glycaemic profile. However, when we divided patients according to the 4 categories of fat distribution (presence or not of lipodystrophy defined by FMR and abdominal prominence), patients with abdominal prominence independent of the presence of lipodystrophy had higher IGT. Moreover, the highest prevalence of DM was observed in patients with lipodystrophy and abdominal prominence (Table 6).

\section{Association between HOMA-IR and body fat mass evaluated by CT and DXA}

After log transformation, significant associations were found between total fat, central fat and central/peripheral fat ratio evaluated by $\mathrm{CT}$ at abdominal level and HOMA-IR. These associations remained significant after adjustments for age, gender, PI, NRTI, NNRTI, CD4 cell count and HIV-1 RNA viral load. On the other hand, no significant association was found between IR and peripheral fat. Similar results were observed when fat distribution was evaluated by DXA. Significant associations were found between total, trunk and arm fat mass evaluated by DXA and HOMA-IR. Also, these associations remained significant after adjustments for age, gender, PI, NRTI, NNRTI, CD4 cell count and HIV-1 RNA viral load (Table 7).

\section{Association between FMR and glycaemic parameters and} insulin resistance

After log transformation, a significant positive linear association was observed between FMR and insulin resistance evaluated by HOMA. This association was independent of age, gender, IP, NRTI, NNRTI, CD4 cell count and HIV-1 RNA viral load. No significant association was observed with the glycaemic parameters (Table 8). We performed linear regression models of the association between FMR and the variables described above, after excluding patients that were on anti-diabetic or insulin therapy, and similar results were obtained (data not shown).

\section{Discussion}

We compared the prevalence of glucose homeostasis disturbances and IR in HIV-infected patients on cART, according to the presence of lipodystrophy (clinically and FMR defined) and according to the four different patterns of body fat distribution previously described. In our study, all the participants were evaluated by the same observer (PF) to increase the accuracy in the clinical definition of lipodystrophy [22]. We also used an objective method to evaluate lipodystrophy to overcome the different and heterogeneous methodologies for the diagnosis of lipodystrophy of previous studies [31]. Since lipodystrophy in HIV-1 infected patients is considered to be an adverse effect of cART, not limited to a specific drug or a class of drugs [32], we chose to study only patients on cART, since our main goal was to compare the

Table 3 Insulin resistance indices according to lipodystrophy defined clinically and by FMR

\begin{tabular}{|c|c|c|c|c|c|c|c|}
\hline \multicolumn{5}{|c|}{ Lipodystrophy defined clinically } & \multicolumn{3}{|c|}{ defined by FMR } \\
\hline & Total & Without CL & With CL & $\mathbf{P}$ & Without L & With L & $P$ \\
\hline HOMA-IR [median (IQR)] & $1.9(2.8)$ & $1.7(2.4)$ & $2.1(3.0)$ & 0.229 & $1.6(2.6)$ & $2.8(2.8)$ & $<0.001$ \\
\hline HOMA-B [median (IQR)] & $92.3(106.4)$ & $92.3(91.1)$ & $91.8(117.5)$ & 0.855 & $92.3(96.1)$ & $85.4(120.8)$ & 0.633 \\
\hline QUICKI [median (IQR)] & $0.34(0.06)$ & $0.35(0.06)$ & $0.34(0.06)$ & 0.229 & $0.36(0.07)$ & $0.33(0.05)$ & $<0.001$ \\
\hline MATSUDA [median (IQR)] & $4.8(5.1)$ & $5.0(4.2)$ & $4.7(5.4)$ & 0.735 & $5.9(5.3)$ & $4.1(4.4)$ & 0.002 \\
\hline Glucose $[\mathrm{mg} / \mathrm{dL}$, median (IQR)] & $93.5(26.0)$ & $90.0(23.0)$ & $97.0(35.5)$ & 0.046 & $90.0(23.0)$ & $97.0(35.5)$ & 0.002 \\
\hline Insulin $[\mu \mathrm{U} / \mathrm{mL}$, median (IQR)] & $8.1(9.6)$ & $7.9(8.2)$ & $9.0(10.2)$ & 0.365 & $7.5(8.1)$ & $10.1(9.9)$ & 0.003 \\
\hline A1c [\% median (IQR)] & $5.3(0.7)$ & $5.2(0.6)$ & $5.3(0.9)$ & 0.091 & $5.2(0.6)$ & $5.5(0.9)$ & 0.002 \\
\hline
\end{tabular}

(CL- clinical lipodystrophy; L- lipodystrophy). 
Table 4 Insulin resistance according to lipodystrophy defined clinically and by FMR

\begin{tabular}{|c|c|c|c|c|c|c|}
\hline & \multicolumn{3}{|c|}{ Lipodystrophy defined clinically } & \multicolumn{3}{|c|}{ Lipodystrophy defined by FMR } \\
\hline & Without CL & With CL & $\mathbf{P}$ & Without L & With L & $\mathbf{P}$ \\
\hline \multicolumn{7}{|l|}{ HOMA -IR } \\
\hline$<4[\mathrm{n}(\%)]$ & $93(80.9)$ & $121(71.6)$ & 0.075 & $94(80.3)$ & $58(65.9)$ & 0.019 \\
\hline$\geq 4[n(\%)]$ & $22(19.1)$ & $48(28.4)$ & & $23(19.7)$ & $30(34.1)$ & \\
\hline \multicolumn{7}{|c|}{ Thirds of HOMA-IR } \\
\hline 1 & $40(34.8)$ & $55(32.5)$ & 0.222 & $51(43.6)$ & $18(20.5)$ & 0.002 \\
\hline 2 & $43(37.4)$ & $51(30.2)$ & & $34(29.1)$ & $33(37.5)$ & \\
\hline 3 & $32(27.8)$ & $63(37.3)$ & & $32(27.4)$ & $37(42.0)$ & \\
\hline
\end{tabular}

(CL- clinical lipodystrophy; L- lipodystrophy).

prevalence of glucose homeostasis disturbances and IR according to the presence of lipodystrophy. No differences were observed between the class of drugs used in patients with or without CL, defined either clinically or by FMR (data not shown). Also, similar results were observed when the comparison was performed in patients with and without lipodystrophy defined by FMR (data not shown). Despite the euglycaemichyperinsulinaemic clamp being the gold standard technique for estimation of IR [33], we used simple methods that have shown a good correlation with the gold standard method (HOMA-IR, QUICKI and MATSUDA) [28,34]. There are studies comparing the prevalence of DM in HIV patients and the general population, and comparing ART-naïve HIV-infected patients with the general population, but fewer compared this prevalence between patients with or without lipodystrophy.

When patients were classified as being lipodystrophic or not, according to FMR, we observed that patients with lipodystrophy had higher IR (higher HOMA and lower QUICKI and Matsuda values). Matsuda index seems to have a greater ability to predict diabetes than its HOMA equivalents [34]. They also had higher fasting plasma glucose, insulin and A1C levels, and higher \% of IFG, IGT and DM. When we categorised patients into 4 categories of body fat distribution using FMR-defined lipodystrophy and waist circumference, those patients with lipodystrophy and abdominal prominence had higher prevalence of DM and IGT. Patients without FMR-defined lipodystrophy but with abdominal prominence only had a high prevalence of IGT. It seems that the loss of peripheral adipose tissue is less important than the presence of abdominal prominence in the occurrence of IR. However, the role of peripheral adipose tissue cannot be completely precluded, since patients with abdominal prominence only and without lipodystrophy, defined by FMR, had less marked glucose disturbances i.e. they only had increased prevalence of IGT. The discrepancy observed between the results obtained using the 2 different lipodystrophy definitions (Tables 3, 5 and 6) could result from the higher accuracy of the objective method in detecting slight losses of peripheral adipose tissue that were not detected by clinical inspection, as has been previously proposed by Bonnet [22].

Significant associations between IR and total fat, central fat and central/peripheral fat ratio and no association with peripheral fat at abdominal level evaluated by CT were observed, emphasizing the contribution of the central fat mass to IR. We found an association between IR and total and trunk fat evaluated by DXA. As in our results, De Wit et al. showed that clinical lipodystrophy was significantly associated with new-onset diabetes and the abnormal body fat distribution in HIV-positive individuals is strongly associated with IR and/or glucose intolerance, with excess trunk or visceral fat being, as in the general population, an important risk factor for IR among those with HIV infection. In addition, De Wit

Table 5 Prevalence of glucose homeostasis abnormalities according to lipodystrophy defined clinically and by FMR

\begin{tabular}{|c|c|c|c|c|c|c|c|}
\hline & \multicolumn{4}{|c|}{ Lipodystrophy defined clinically } & \multicolumn{3}{|c|}{ Lipodystrophy defined by FMR } \\
\hline & Total $(n=228)$ & Without CL $(n=89)$ & With $C L(n=129)$ & $\mathbf{P}$ & Without L $(n=100)$ & With L $(n=70)$ & $\mathbf{P}$ \\
\hline NG [n (\%)] & $117(49.1)$ & $44(49.4)$ & $63(48.8)$ & 0.364 & $62(62.0)$ & $29(41.4)$ & 0.021 \\
\hline IFG [n (\%)] & $18(8.3)$ & $10(11.2)$ & $8(6.2)$ & & $5(5.0)$ & $11(15.7)$ & \\
\hline IGT [n (\%)] & $49(22.5)$ & $21(23.6)$ & $28(21.7)$ & & $19(19.0)$ & $15(21.4)$ & \\
\hline $\mathrm{DM}[\mathrm{n}(\%)]$ & $44(20.2)$ & $14(15.7)$ & $30(23.3)$ & & $14(14.0)$ & $15(21.4)$ & \\
\hline
\end{tabular}

(NG- normal glucose; IFG - impaired fasting glucose: IGT - impaired glucose tolerance; DM - diabetes mellitus; CL - clinical lipodystrophy; L - lipodystrophy; L-lipodystrophy). 
Table 6 Prevalence of glucose homeostasis abnormalities according to body composition categorised into 4 groups of fat distribution

\begin{tabular}{|c|c|c|c|c|c|c|c|c|c|c|}
\hline \multicolumn{6}{|c|}{ Categories of fat distribution by clinical lipoatrophy and WC } & \multicolumn{5}{|c|}{ Categories of fat distribution by FMR and WC } \\
\hline & CLA- AP- & CLA-AP+ & $\mathrm{CLA}+\mathrm{AP}-$ & $\mathrm{CLA}+\mathrm{AP}+$ & $\mathbf{P}$ & L- AP- & L-AP+ & $L+A P-$ & $\mathrm{L}+\mathrm{AP}+$ & $\mathbf{P}$ \\
\hline NG [n (\%)] & $17(56.7)$ & $27(45.8)$ & $41(58.6)$ & $22(37.3)$ & 0.064 & $39(61.9)$ & $32(50.8)$ & $19(51.4)$ & $17(30.9)$ & 0.002 \\
\hline IFG [n (\%)] & $1(3.3)$ & $9(15.3)$ & $4(5.7)$ & $4(6.8)$ & & $0(0.0)$ & $7(11.1)$ & $5(13.5)$ & $6(10.9)$ & \\
\hline IGT [n (\%)] & $5(16.7)$ & $16(27.1)$ & 10 (14.3) & 18 (30.5) & & $9(14.3)$ & $17(27.0)$ & $6(16.2)$ & $17(30.9)$ & \\
\hline $\mathrm{DM}$ [n (\%)] & $7(23.3)$ & $7(11.9)$ & $15(21.4)$ & $15(25.4)$ & & $15(23.8)$ & $7(11.1)$ & 7 (18.9) & $15(27.3)$ & \\
\hline
\end{tabular}

(NG- normal glucose; IFG - impaired fasting glucose: IGT - impaired glucose tolerance; DM - diabetes mellitus; CLA - Clinical lipoatrophy; AP - abdominal prominence defined by waist circumference $>80 \mathrm{~cm}$ in women and $>94 \mathrm{~cm}$ in men - IDF 2005; L- lipodystrophy FMR defined; CLA-AP-: no lipodystrophy; CLA-AP+: isolated central fat accumulation; $C L A+A P-:$ isolated lipoatrophy; CLA + AP+: mixed forms of lipodystrophy).

observed that IR is itself independently associated with fat loss in HIV-positive individuals [5].

In our sample, no association was observed between peripheral fat mass and IR (Table 7). This result is contrary to that of the De Wit study, where patients had a marked peripheral adipose tissue loss that was clinically evident. Also, our patients may have had less evident loss of fat mass, which was detected by FMR. In fact, according to De Wit's conclusions, information on lipodystrophy was rarely collected since the study was carried out in 11 centres, which may suggest that only marked lipodystrophies were reported.

The dual contribution of peripheral fat loss and increased abdominal fat has also been described by other authors [35-38]. Furthermore, hyperinsulinaemia seems to be more severe among the patients with a combined fat redistribution syndrome.

In our HIV-infected sample, we had a high prevalence of diabetes (20.2\%), of IGT (22.5\%) and IFG (8.3\%). This high prevalence could not be extrapolated for the total HIV population since we could have a referral bias, but we would like to emphasize that our aim was to

Table 7 Association between HOMA-IR and body fat mass evaluated by CT and DXA

\begin{tabular}{|c|c|c|c|c|c|c|}
\hline & \multicolumn{2}{|c|}{ Crude model } & \multicolumn{2}{|c|}{ Model 1* } & \multicolumn{2}{|c|}{ Model $2^{* *}$} \\
\hline & $\beta$ & $\mathbf{P}$ & $\beta$ & $\mathbf{P}$ & $\beta$ & $\mathbf{p}$ \\
\hline \multicolumn{7}{|c|}{ Body Fat Mass by Quantitative CT } \\
\hline Total Fat & 0.384 & 0.001 & 0.419 & 0.001 & 0.415 & 0.001 \\
\hline Central Fat & 0.516 & $<0.001$ & 0.486 & $<0.001$ & 0.490 & $<0.001$ \\
\hline Peripheral Fat & 0.050 & 0.530 & 0.127 & 0.168 & 0.114 & 0.222 \\
\hline Central/peripheral fat ratio & 0.258 & 0.001 & 0.239 & 0.015 & 0.262 & 0.008 \\
\hline \multicolumn{7}{|l|}{ Body fat mass by DXA } \\
\hline Total & 0.247 & 0.024 & 0.374 & 0.002 & 0.420 & 0.001 \\
\hline Trunk & 0.403 & $<0.001$ & 0.467 & $<0.001$ & 0.502 & $<0.001$ \\
\hline Leg & -0.043 & 0.625 & 0.049 & 0.653 & 0.087 & 0.438 \\
\hline Arm & 0.162 & 0.058 & 0.352 & 0.001 & 0.366 & 0.00 \\
\hline
\end{tabular}

*-Mode1: adjusted for age and gender.

**-Model 2: adjusted for age, gender, IP, NRTI, CD4 cell count and HIV-1 RNA viral load.

(DXA -dual-energy X-ray absorptiometry; CT - computed tomography). evaluate the prevalence of glucose homeostasis disturbances and IR according to the presence of lipodystrophy. In HIV-infected patients, some studies showed a low prevalence of diabetes, around $3.0 \%$, but without performing OGTT, which could have resulted in some under-identification of glucose disturbances [39]. Others suggested that the prevalence and incidence of diabetes was higher (10-14 \%) [7,8,40-42] but still lower than that which we observed. Concerning HIV-associated lipodystrophy, Carr found a baseline diabetes prevalence of $2 \%$ [43] and an over threefold increase after 14 months of follow-up [44], which suggests that lipodystrophy strongly promotes the progression to hyperglycaemia. The overall prevalence of all glucose disturbances (DM, IFG and IGT) was $25 \%$ [43]. In the Lipodystrophy Case Definition Study, diabetes prevalence was $7 \%$ in those with lipodystrophy and $3 \%$ in those without [45].

It is extremely difficult to determine which drug is responsible for the risk of diabetes because they are always used in combination and therapeutic changes in individual participants often occur during the course of the disease. The results are generally consistent, indicating a higher risk of diabetes with use of NRTI and NNRTI $[46,47]$. Also, others have shown that regimens containing PI are associated with new-onset diabetes and IR $[48,49]$. cART has direct effects on glucose metabolism, or exerts its effect on glucose metabolism indirectly by affecting changes in body composition. PIs directly and/ or indirectly alter body composition, lipid profile, adipokine levels, and mediators of inflammation. The newer

Table 8 Association between FMR and glycaemic parameters and insulin resistance

\begin{tabular}{|c|c|c|c|c|c|c|}
\hline & \multicolumn{2}{|c|}{ Crude model } & \multicolumn{2}{|c|}{ Model 1* } & \multicolumn{2}{|c|}{ Model $2^{* *}$} \\
\hline & $\beta$ & $\mathbf{P}$ & $\beta$ & $\mathbf{P}$ & $\beta$ & $p$ \\
\hline HOMA & 0.589 & $<0.001$ & 0.595 & 0.001 & 0.266 & 0.002 \\
\hline Glucose $0^{\prime}$ & 0.124 & 0.002 & 0.041 & 0.367 & 0.098 & 0.222 \\
\hline Glucose $2 \mathrm{~h}$ & 0.079 & 0.142 & 0.086 & 0.139 & 0.149 & 0.104 \\
\hline $\mathrm{A} 1 \mathrm{C}$ & 0.053 & 0.015 & 0.007 & 0.765 & 0.083 & 0.314 \\
\hline
\end{tabular}

*-Mode1: adjusted for age and gender.

**-Model 2: adjusted for age, gender, IP, NRTI, CD4 cell count and HIV-1 RNA viral load. 
CART regimens may be less detrimental to insulin action than older regimens.

In our study, FMR as a continuum was significantly associated with insulin resistance evaluated by HOMA, even after adjustment for gender, age, IP, NRTI, NNRTI, CD4 cell count and HIV RNA viral load. No association between clinical and FMR-defined lipodystrophy and glycaemic parameters was observed.

The association between fat redistribution, glucose disturbances, IR and cART, might be explained through several mechanisms: lipoatrophy per se; lipotoxicity (cART or visceral fat-induced or both, demonstrated by increased lipolysis and circulating free fatty acids) [2]; inflammation (resulting from the infection and demonstrated by increased TNF-alpha production, increased serum concentrations of the soluble type 2 receptor of TNF-alpha [39] and other interleukins), and hormonal factors (leptin, resistin or adiponectin).

We should keep in mind that IR and diabetes are associated with age, so increased life expectancy with the use of cART is likely to increase the prevalence of diabetes [7].

The net risk of diabetes mellitus is determined by a complex interplay of individual factors, combining the traditional risk factors and newer risk factors associated with HIV-infected patients on cART. The clinical implications and message should be the need to aggressively screen for, prevent, and treat diabetes mellitus among HIV-infected patients because the presence of diabetes increases the risk of a future CHD event by almost 2.5 times [7].

\section{Our study has some limitations}

Although all patients referred from Infectious Diseases to our department were included, bias in the referral cannot be excluded, since some patients could have been referred because they had some degree of glucose intolerance or dyslipidaemia. It was not our aim to determine the prevalence of glucose homeostasis disturbances in the HIV population, because these patients are not representative of the general HIV population in our country. Our aim was to compare the prevalence of glucose homeostasis disturbances and IR in HIV-infected patients according the presence of lipodystrophy and to different patterns of fat distribution.

Also, information regarding other important risk factors for DM (e.g. family history, physical inactivity) was not collected and could not be analysed. Some drugs used for managing complications of HIV infection may be associated with worsening IR or DM; we believe that if there was any effect it was very small, since none of our patients were on niacin, megestrol acetate or steroids, and only some of them were on thiazides for the management of hypertension.

\section{Some aspects of this study should be highlighted}

The study was performed in a unit that is highly experienced in the assessment of metabolic and body fat abnormalities in HIV-infected patients; the clinical assessment of lipodystrophy was carried out by the same investigator (PF); and an objective definition of lipodystrophy (Fat Mass Ratio by DXA), visceral and subcutaneous fat mass by CT was used.

\section{Conclusions}

Insulin resistance and glucose homeostasis abnormalities significantly increased with increasing FMR. Abdominal prominence, measured by abdominal circumference, waist/hip ratio, visceral and trunk fat defined by CT, was also associated with glucose homeostasis disturbances.

Although no association between glucose disturbances and IR was observed in clinically defined lipodystrophy, when this condition was defined by FMR, a significant positive association was observed.

\section{Competing interest}

None to declare.

\section{Authors' contributions}

PF conceived the study, participated in its design, in the acquisition of data and drafted the manuscript; DC conceived the study, participated in its design and drafted the manuscript; ACS performed the statistical analysis and revised critically the manuscript; JM participated in the acquisition of data and drafted the manuscript; MJM participated in the acquisition of data; AJM performed the CT scan and reviewed the data; EM and AS critically revised the manuscript; JLM revised the study design. All authors read and approved the final manuscript.

\section{Funding}

Research Fellowship Dr. Manuel Almeida Ruas, Portuguese Society of Diabetology. Research Fellowship of the Portuguese Association for Clinical Study of AIDS. Research Grant to support doctoral studies in the area of HIV/ AIDS, GlaxoSmithKline Foundation of Health Sciences.

\section{Author details}

'Department of Endocrinology, Hospital de São João, University of Porto Medical School, Alameda Hernâni Monteiro, 4200, Porto Portugal, Portugal. ${ }^{2}$ Department of Endocrinology, Hospital de São João, University of Porto Medical School, Porto, Portugal. ${ }^{3}$ Department of Clinical Epidemiology, Predictive Medicine and Public Health, University of Porto Medical School, and University of Porto Institute of Public Health, Porto, Portugal. ${ }^{4}$ Department of Endocrinology, Hospital de São João, University of Porto Medical School, Porto, Portugal. ${ }^{5}$ Department of Endocrinology, Hospital de São João, University of Porto Medical School, Porto, Portugal. ${ }^{6}$ Department of Radiology, Hospital de São João, University of Porto Medical School, Porto, Portugal. ${ }^{7}$ Department of Infectious Diseases, Hospital Clinic, University of Barcelona Medical School, Barcelona, Spain. ${ }^{8}$ Department of Infectious Disease, Hospital de São João, University of Porto Medical School, Porto, Portugal. ${ }^{9}$ Department of Endocrinology, Hospital de São João, University of Porto Medical School, Porto, Portugal.

Received: 27 February 2012 Accepted: 13 July 2012

Published: 6 August 2012

\section{References}

1. Palella FJ Jr: Delaney KM, Moorman AC, Loveless MO, Fuhrer J, Satten GA Aschman DJ. Holmberg SD: Declining morbidity and mortality among patients with advanced human immunodeficiency virus infection. HIV Outpatient Study Investigators. N Engl J Med 1998, 338(13):853-860. 
2. Samaras K: Prevalence and pathogenesis of diabetes mellitus in HIV-1 infection treated with combined antiretroviral therapy. J Acquir Immune Defic Syndr 2009, 50(5):499-505.

3. Noor MA, Seneviratne T, Aweeka FT, Lo JC, Schwarz JM, Mulligan K, Schambelan M, Grunfeld C: Indinavir acutely inhibits insulin-stimulated glucose disposal in humans: a randomized, placebo-controlled study. AIDS 2002, 16(5):F1-8.

4. Lee GA, Lo JC, Aweeka F, Schwarz JM, Mulligan K, Schambelan M, Grunfeld C: Single-dose lopinavir-ritonavir acutely inhibits insulin-mediated glucose disposal in healthy volunteers. Clin Infect Dis 2006, 43(5):658-660.

5. De Wit S, Sabin CA, Weber R, Worm SW, Reiss P, Cazanave C, El-Sadr W, Monforte A, Fontas E, Law MG, Friis-Moller N, Phillips A: Incidence and risk factors for new-onset diabetes in HIV-infected patients: the Data Collection on Adverse Events of Anti-HIV Drugs (D:A:D) study. Diabetes Care 2008, 31(6):1224-1229.

6. Brown TT, Li X, Cole SR, Kingsley LA, Palella FJ, Riddler SA, Chmiel JS, Visscher BR, Margolick JB, Dobs AS: Cumulative exposure to nucleoside analogue reverse transcriptase inhibitors is associated with insulin resistance markers in the Multicenter AIDS Cohort Study. AIDS 2005 19(13):1375-1383.

7. Worm SW, De Wit S, Weber R, Sabin CA, Reiss P, El-Sadr W, Monforte AD, Kirk O, Fontas E, Dabis F, Law MG, Lundgren JD, Friis-Moller N: Diabetes mellitus, preexisting coronary heart disease, and the risk of subsequent coronary heart disease events in patients infected with human immunodeficiency virus: the Data Collection on Adverse Events of AntiHIV Drugs (D:A:D Study). Circulation 2009, 119(6):805-811.

8. Friis-Moller N, Weber $R$, Reiss $P$, Thiebaut R, Kirk O: d'Arminio Monforte A, Pradier C, Morfeldt L, Mateu S, Law M, El-Sadr W, De Wit S, Sabin CA, Phillips AN, Lundgren JD: Cardiovascular disease risk factors in HIV patients-association with antiretroviral therapy. Results from the DAD study. AIDS 2003, 17(8):1179-1193.

9. Glass TR, Ungsedhapand C, Wolbers M, Weber R, Vernazza PL, Rickenbach M, Furrer H, Bernasconi E, Cavassini M, Hirschel B, Battegay M, Bucher HC: Prevalence of risk factors for cardiovascular disease in HIV-infected patients over time: the Swiss HIV Cohort Study. HIV Med 2006, 7(6):404-410.

10. Santos J, Palacios R, Gonzalez M, Ruiz J, Marquez M: Atherogenic lipid profile and cardiovascular risk factors in HIV-infected patients (Netar Study). Int J STD AIDS 2005, 16(10):677-680.

11. Grinspoon SK, Grunfeld C, Kotler DP, Currier JS, Lundgren JD, Dube MP, Lipshultz SE, Hsue PY, Squires K, Schambelan M, Wilson PW, Yarasheski KE, Hadigan CM, Stein JH, Eckel RH: State of the science conference: Initiative to decrease cardiovascular risk and increase quality of care for patients living with HIV/AIDS: executive summary. Circulation 2008, 118(2):198-210.

12. Hadigan C, Meigs JB, Corcoran C, Rietschel P, Piecuch S, Basgoz N, Davis B, Sax P, Stanley T, Wilson PW, D'Agostino RB, Grinspoon S: Metabolic abnormalities and cardiovascular disease risk factors in adults with human immunodeficiency virus infection and lipodystrophy. Clin Infect Dis 2001, 32(1):130-139.

13. Currier JS, Taylor A, Boyd F, Dezii CM, Kawabata H, Burtcel B, Maa JF, Hodder S: Coronary heart disease in HIV-infected individuals. J Acquir Immune Defic Syndr 2003, 33(4):506-512.

14. Carr A, Samaras K, Chisholm DJ, Cooper DA: Pathogenesis of HIV-1protease inhibitor-associated peripheral lipodystrophy, hyperlipidaemia, and insulin resistance. Lancet 1998, 351(9119):1881-1883.

15. van der Valk M, Bisschop PH, Romijn JA, Ackermans MT, Lange JM, Endert E, Reiss P, Sauerwein HP: Lipodystrophy in HIV-1-positive patients is associated with insulin resistance in multiple metabolic pathways. AIDS 2001, 15(16):2093-2100.

16. Human immunodeficiency virus (HIV) infection codes and new codes for Kaposi's sarcoma. MMWR Recomm Rep 1991, 40(RR-9):1-18.

17. Freitas P, Santos AC, Carvalho D, Pereira J, Marques R, Martinez E, Sarmento A, Medina JL: Fat mass ratio: an objective tool to define lipodystrophy in hiv-infected patients under antiretroviral therapy. J Clin Densitom 2010, 13(2):197-203

18. Freitas $P$, Carvalho D, Souto S, Santos AC, Xerinda S, Marques R, Martinez E, Sarmento A, Medina JL: Impact of Lipodystrophy on the prevalence and components of metabolic syndrome in HIV-infected patients. BMC Infect Dis 2011, 11:246.

19. Freitas $P$, Carvalho D, Santos AC, Mesquita J, Correia F, Xerinda S, Marques R, Martinez E, Sarmento A, Medina JL: Assessment of body fat composition disturbances by bioimpedance analysis in HIV-infected adults. J Endocrinol Invest 2011.

20. Freitas P, Carvalho D, Santos AC, Matos MJ, Madureira AJ, Marques R Martinez E, Sarmento A, Medina JL: Prevalence of obesity and its relationship to clinical lipodystrophy in HIV-infected adults on antiretroviral therapy. J Endocrinol Invest 2011, AA:AA-AA.

21. Alberti KG, Eckel RH, Grundy SM, Zimmet PZ, Cleeman Jl, Donato KA, Fruchart JC, James WP, Loria CM, Smith SC Jr: Harmonizing the metabolic syndrome: a joint interim statement of the International Diabetes Federation Task Force on Epidemiology and Prevention; National Heart, Lung, and Blood Institute; American Heart Association; World Heart Federation; International Atherosclerosis Society; and International Association for the Study of Obesity. Circulation 2009, 120(16):1640-1645

22. Bonnet E, Delpierre C, Sommet A, Marion-Latard F, Herve R, Aquilina C, Labau E, Obadia M, Marchou B, Massip P, Perret B, Bernard J: Total body composition by DXA of 241 HIV-negative men and 162 HIV-infected men: proposal of reference values for defining lipodystrophy. J Clin Densitom 2005, 8(3):287-292.

23. van der Kooy K, Seidell JC: Techniques for the measurement of visceral fat: a practical guide. Int J Obes Relat Metab Disord 1993, 17(4):187-196.

24. Yoshizumi T, Nakamura T, Yamane M, Islam AH, Menju M, Yamasaki K, Arai T, Kotani K, Funahashi T, Yamashita S, Matsuzawa Y: Abdominal fat: standardized technique for measurement at CT. Radiology 1999, 211(1):283-286

25. American Diabetes Association: Diagnosis and classification of diabetes mellitus (Position Statement). Diabetes Care 2009, 32(Suppl 1):S62-S67.

26. Matthews DR, Hosker JP, Rudenski AS, Naylor BA, Treacher DF, Turner RC Homeostasis model assessment: insulin resistance and beta-cell function from fasting plasma glucose and insulin concentrations in man. Diabetologia 1985, 28(7):412-419.

27. Katz A, Nambi SS, Mather K, Baron AD, Follmann DA, Sullivan G, Quon MJ: Quantitative insulin sensitivity check index: a simple, accurate method for assessing insulin sensitivity in humans. J Clin Endocrinol Metab 2000, 85(7):2402-2410.

28. Matsuda M, DeFronzo RA: Insulin sensitivity indices obtained from oral glucose tolerance testing: comparison with the euglycemic insulin clamp. Diabetes Care 1999, 22(9):1462-1470.

29. Bonora E, Kiechl S, Willeit J, Oberhollenzer F, Egger G, Targher G, Alberiche M, Bonadonna RC, Muggeo M: Prevalence of insulin resistance in metabolic disorders: the Bruneck Study. Diabetes 1998, 47(10):1643-1649

30. Haffner SM, Kennedy E, Gonzalez C, Stern MP, Miettinen H: A prospective analysis of the HOMA model. The Mexico City Diabetes Study. Diabetes Care 1996, 19(10):1138-1141.

31. Freitas P, Santos AC, Carvalho D, Pereira J, Marques R, Martinez E, Sarmento A, Medina JL: Fat Mass Ratio: An Objective Tool to Define Lipodystrophy in HIV-Infected Patients Under Antiretroviral Therapy. J Clin Densitom 2010.

32. Lichtenstein KA: Redefining lipodystrophy syndrome: risks and impact on clinical decision making. J Acquir Immune Defic Syndr 2005, 39(4):395-400.

33. DeFronzo RA, Tobin JD, Andres R: Glucose clamp technique: a method for quantifying insulin secretion and resistance. Am J Physiol 1979, 237(3):E214-223.

34. Carlos Lorenzo HPH, Haffner SM: Insulin Resistance and Excess Risk of Diabetes in Mexican-Americans: The San Antonio Heart Study. J Clin Endocrinol Metab 2012, 3:97.

35. Grunfeld C, Rimland D, Gibert CL, Powderly WG, Sidney S, Shlipak MG, Bacchetti P, Scherzer R, Haffner S, Heymsfield SB: Association of upper trunk and visceral adipose tissue volume with insulin resistance in control and HIV-infected subjects in the FRAM study. J Acquir Immune Defic Syndr 2007, 46(3):283-290.

36. Meininger G, Hadigan C, Rietschel P, Grinspoon S: Body-composition measurements as predictors of glucose and insulin abnormalities in HIVpositive men. Am J Clin Nutr 2002, 76(2):460-465.

37. Gan SK, Samaras K, Thompson CH, Kraegen EW, Carr A, Cooper DA, Chisholm DJ: Altered myocellular and abdominal fat partitioning predict disturbance in insulin action in HIV protease inhibitor-related lipodystrophy. Diabetes 2002, 51(11):3163-3169.

38. Mynarcik DC, McNurlan MA, Steigbigel RT, Fuhrer J, Gelato MC: Association of severe insulin resistance with both loss of limb fat and elevated serum tumor necrosis factor receptor levels in HIV lipodystrophy. $J$ Acquir Immune Defic Syndr 2000, 25(4):312-321. 
39. Brar I, Shuter J, Thomas A, Daniels E, Absalon J: A comparison of factors associated with prevalent diabetes mellitus among HIV-Infected antiretroviral-naive individuals versus individuals in the National Health and Nutritional Examination Survey cohort. J Acquir Immune Defic Syndr 2007, 45(1):66-71.

40. Brown TT, Cole SR, Li X, Kingsley LA, Palella FJ, Riddler SA, Visscher BR, Margolick JB, Dobs AS: Antiretroviral therapy and the prevalence and incidence of diabetes mellitus in the multicenter AIDS cohort study. Arch Intern Med 2005, 165(10):1179-1184.

41. Butt AA, Fultz SL, Kwoh CK, Kelley D, Skanderson M, Justice AC: Risk of diabetes in HIV infected veterans pre- and post-HAART and the role of HCV coinfection. Hepatology 2004, 40(1):115-119.

42. Howard AA, Floris-Moore M, Arnsten JH, Santoro N, Fleischer N, Lo Y, Schoenbaum EE: Disorders of glucose metabolism among HIV-infected women. Clin Infect Dis 2005, 40(10):1492-1499.

43. Carr A, Samaras K, Thorisdottir A, Kaufmann GR, Chisholm DJ, Cooper DA: Diagnosis, prediction, and natural course of HIV-1 protease-inhibitorassociated lipodystrophy, hyperlipidaemia, and diabetes mellitus: a cohort study. Lancet 1999, 353(9170):2093-2099.

44. Carr A, Samaras K, Burton S, Law M, Freund J, Chisholm DJ, Cooper DA: A syndrome of peripheral lipodystrophy, hyperlipidaemia and insulin resistance in patients receiving HIV protease inhibitors. AIDS 1998, 12(7):F51-58.

45. Carr A, Emery S, Law M, Puls R, Lundgren JD, Powderly WG: An objective case definition of lipodystrophy in HIV-infected adults: a case-control study. Lancet 2003, 361(9359):726-735.

46. Tien PC, Schneider MF, Cole SR, Levine AM, Cohen M, DeHovitz J, Young M, Justman JE: Antiretroviral therapy exposure and incidence of diabetes mellitus in the Women's Interagency HIV Study. AIDS 2007, 21(13):1739-1745.

47. Butt AA, McGinnis K, Rodriguez-Barradas MC, Crystal S, Simberkoff M, Goetz $M B$, Leaf $D$, Justice $A C$ : HIV infection and the risk of diabetes mellitus. AIDS 2009, 23(10):1227-1234.

48. Mulligan K, Grunfeld C, Tai WW, Algren H, Pang M, Chernoff DN, Lo JC, Schambelan M: Hyperlipidemia and insulin resistance are induced by protease inhibitors independent of changes in body composition in patients with HIV infection. J Acquir Immune Defic Syndr 2000, 23(1):35-43.

49. Behrens G, Dejam A, Schmidt H, Balks HJ, Brabant G, Korner T, Stoll M, Schmidt RE: Impaired glucose tolerance, beta cell function and lipid metabolism in HIV patients under treatment with protease inhibitors. AIDS 1999, 13(10):F63-70

doi:10.1186/1471-2334-12-180

Cite this article as: Freitas et al.: Lipodystrophy defined by Fat Mass Ratio in HIV-infected patients is associated with a high prevalence of glucose disturbances and insulin resistance. BMC Infectious Diseases 2012 $12: 180$

\section{Submit your next manuscript to BioMed Central and take full advantage of:}

- Convenient online submission

- Thorough peer review

- No space constraints or color figure charges

- Immediate publication on acceptance

- Inclusion in PubMed, CAS, Scopus and Google Scholar

- Research which is freely available for redistribution 